\title{
Analisis Gaya Berat di Trangkil Gunungpati Semarang
}

\author{
Annisa Faurina Lestari ${ }^{1}$, Niken Tri Widayati ${ }^{1}$, Rusman $^{1,{ }^{*}}$, Supriyadi ${ }^{1}$, Khumaedi $^{1}$ \\ ${ }^{1}$ Pascasarjana Pendidikan Fisika, Universitas Negeri Semarang, Jalan Kelud Utara Semarang 50237, \\ Indonesia \\ *email korespondensi: rusmanbintara1990@gmail.com
}

Received : 3 Januari 2020; Revised : 22 Januari 2020; Accepted : 7 September 2020; Published : 20 Oktober 2020

\section{ABSTRAK}

Telah dilakukan suatu penelitian tentang analisis struktur bawah permukaan di daerah Trangkil, Gunung Pati, Semarang, Jawa Tengah berdasarkan data gaya berat. Latar belakang dari penelitian ini adalah bahwa daerah Trangkil merupakan daerah yang telah dinyatakan rawan longsor oleh Direktorat Geologi Tata Lingkungan. Penetapan daerah Trangkil sebagai daerah rawan longsor dinyatakan setelah pada tanggal 23 Januari 2014 daerah tersebut mengalami bencana longsor besar yang menyebabkan beberapa rumah rusak parah. Oleh karena itu, perlu dilakukan penelitian geoteknik yang memanfaatkan metode gravitasi atau gaya berat, sehingga struktur bawah permukaan daerah trangkil dapat diketahui. Metode yang digunakan dalam penelitian ini adalah metode gaya berat. Metode gaya berat adalah salah satu metode geofisika yang menggunakan disribusi parameter percepatan gaya berat di permukaan bumi. Faktor-faktor yang mempengaruhi nilai variasi percepatan gaya berat bumi antara lain densitas batuan (kerapatan massa), kondisi morfologi, pasang surut, udara bebas, bentuk bumi dan lain-lain. Variasi densitas bawah permukaan tanah adalah faktor yang sangat berpengaruh dalam penentuan penyebaran anomaly gaya berat secara geofisika. Pengumpulan data dilakukan dengan menggunakan alat Gravity Meter, yang selanjutnya dilakukan pengolahan data meliputi proses koreksi yaitu tahapan pengolahan data gaya berat hasil observasi di lapangan. Hasil Simple Bougier Anomaly (SBA) untuk anomaly pada daerah penelitian berkisar di antara 0,5 mGal - 7,5 mGal. Hasil Complete Bougier Anomaly (CBA) untuk anomaly pada daerah penelitian berkisar di antara 0,5 mGal - 7,5 mGal.

Kata-kata kunci: gaya berat; Gravity Meter; Trangkil

\section{PENDAHULUAN}

Lapisan kerak benua dan kerak samudera adalah susunan lapisan bumi paling luar yang mengandung perbedaan nilai kerapatan massa (densitas) yang sangat berpengaruh terhadap medan gravitasi. Oleh karena itu, variasi nilai percepatan gravitasi (anomaly gravitasi) sering terjadi. Percepatan gravitasi adalah peristiwa terjadinya medan antara dua massa yang saling berinteraksi. Interaksi massa tersebut berupa adanya gaya tarik-menarik yang menyebabkan kedua benda mengalami percepatan dan arahnya saling berlawanan. Metode gravitasi adalah salah satu metode geofisika yang bersifat pasif atau menggunakan sumber alami dan didasari oleh hukum newton untuk gravitasi universal. Metode gravitasi ini menggunakan variasi kerapatan massa yang terdistribusi dalam lapisan tanah. Setiap batuan atau material dalam tanah memiliki nilai kerapatan massa yang berbeda-beda dan dapat mempengaruhi variasi medan gravitasi bumi, sehingga menyebabkan terjadi anomaly gravitasi (Jaenudin, 2012).

Pencarian dan eksplorasi sumber energi merupakan salah satu aktivitas yang sangat membutuhkan peran dari metode gravitasi atau gaya berat. Metode gaya berat digunakan untuk mendeteksi batuan dibawah permukaan. Selain itu, Eksplorasi gaya berat dimulai pada awal abad 20 untuk penemuan minyak dan gas bumi pertama kali. Sejak saat itu metode gaya berat terus mengalami kemajuan baik dalam hal instrumentasi, akuisisi, pengolahan maupun interpretasi data (Muset \& Khan dalam Torkis, 2012).

Penelitian gaya berat ini dilakukan di daerah Trangkil, Kelurahan Sukorejo, Kecamatan Gunungpati, Kabupaten Semarang. Daerah ini telah lama dinyatakan sebagai daerah rawan longsor oleh Direktorat Geologi Tata Lingkungan, Bandung. Salah satu peristiwa longsor terparah yang terjadi pada daerah Trangkil adalah pada hari Kamis, 23 Januari 2014 pukul 07.30 WIB yang menyebabkan perumahan Trangkil Baru RT 6 RW 10, dengan 32 rumah mengalami rusak parah, bahkan beberapa rumah rata dengan tanah. Oleh karena itu, evaluasi geoteknik untuk menunjang efektivitas pemilihan desain perkuatan lereng, diperlukan pemahaman tentang sifat fisik dan mekanis dari tanah berdasarkan serangkaian pengujian tanah (Cahyo, Nogroho \& Widodo, 2014). 


\section{EKSPERIMEN}

Struktur bawah permukaan dapat diketahui melalui metode gaya berat. Dalam penelitian inidimulai dengan merumuskan masalah penelitian dan dilanjutkan dengan pengumpulan data dari lokasi penelitian yaitu di daerah Trangkil, Gunung Pati, Semarang. Pengumpulan data menggunakan alat Gravity Meter, penggunaan alat Gravity Meter sesuai dengan standar operasional prosedur yang telah ditentukan. Secara garis besar penggunaan Gravity Meter dimulai dengan mengkalibrasi alat, mengoreksi data dengan metode yang telah ditentukan dan menentukan rapat massa rata-rata. Setelah memiliki data, selanjutnya melakukan studi literatur untuk mengumpulkan dan mempelajari informasi yang berkaitan dengan penelitian sehingga penelitian berjalan lancar dan sesuai dengan tujuan penelitian yang telah ditentukan.

Langkah ketiga melakukan pengolahan data melalui proses koreksi yaitu mengolah data gaya berat hasil observasi di lapangan. Koreksi yang digunakan yaitu koreksi bouguer dengan mencari nilai tarikan gravitasi yang disebabkan batuan berupa slab dengan ketebalan $\mathrm{H}$ dan kerapatan rata-rata $\rho$. Koreksi dilakukan dengan cara mengurangi atau menambahkan nilai gravitasi terhadap nilai koreksi bouguer sehingga diperoleh nilai Simple Bourguer Anomaly (SBA). Dalam pengolahan data dilakukan pula koreksi medan yang berfungsi mengakomodir ketidak teraturan pada tofografi sekitar titik pengukuran. Koreksi medan pada tiap bagian dihitung dengan persamaan berikut.

$$
T C=\left(0,04191 \frac{\rho}{n}\left[r_{2}-r_{1}+\sqrt{r_{1}^{2}+z^{2}}-\sqrt{r_{2}^{2}+z^{2}}\right]\right)
$$

Dimana :

TC : terrain correction (mGal)

$r_{1} \quad$ : diameter dalam $(\mathrm{m})$

$r_{2} \quad$ : diameter luar $(\mathrm{m})$

$\mathrm{n} \quad$ : jumlah segmen dalam zona

z $\quad$ : perbedaan elevasi rata-rata kompartemen

Karena komponen gaya horizontal (koreksi medan) bersifat mengurangi nilai gaya berat terukur, maka koreksi medan harus ditambahkan pada SBA, sehingga anomali menjadi CBA.

$$
C B A=S B A+T C
$$

Dimana :

CBA : Complete Bougieer Anomaly (mGal)

SBA : Simple Bougier Anomaly (mGal)

TC : Terrain Correction (mGal)

Langkah keempat yaitu menganalisa hasil pengolahan atau hasil koreksi data serta model struktur bawah permukaan yang telah dibuat agar diperoleh kesimpulan dan penyelesaian masalah yang dihadapi. Langkah terakhir membuat kesimpulan dari hasil penelitian. Berikut diagram alur penelitian yang ditunjukan pada Gambar 1.

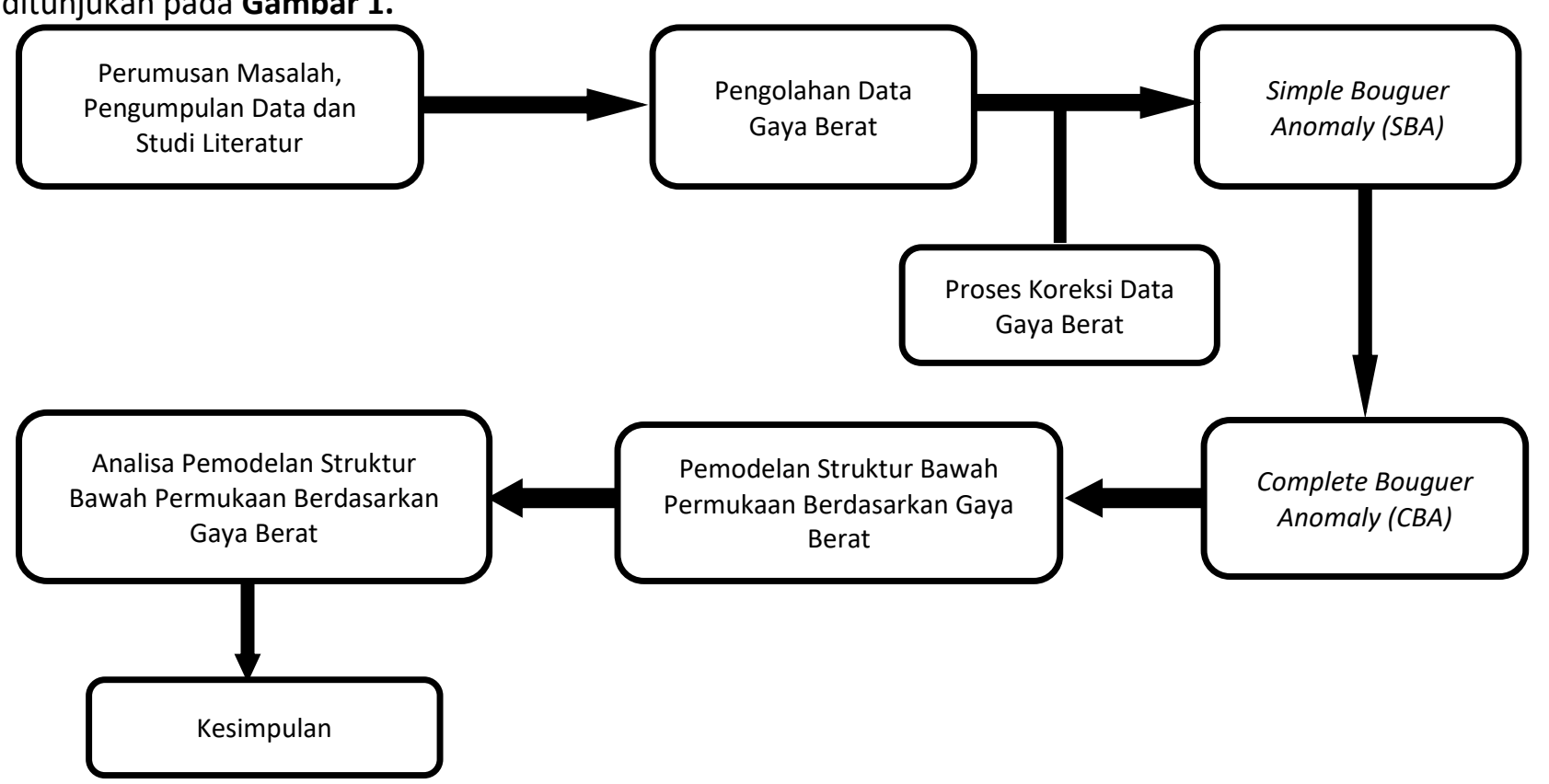

Gambar 1.Diagram Alur Penelitian 


\section{HASIL DAN DISKUSI}

Pengolahan terhadap data lapangan, didapatkan nilai untuk gaya berat (Bouger anomaly). Proses interpretasi terhadap hasil pengolahan data, dilakukan dengan pembuatan kontur nilai pada anomaly gaya berat (Bougier anomaly). Gambar 2 menjelaskan peta topografi untuk wilayah penelitian Trangkil, Desa Sukoharjo Kecamatan Gunungpati Semarang. Peta topografi digunakan untuk menyajikan obyek-obyek di permukaan bumi dengan memiliki ketinggian yang dapat dihitunh berdasarkan permukaan air laut dan digambarkan dalam bentuk kontur, dengan artian setiap garis mewakili satu ketinggian (Afani, Yuwono \& Bashit, 2019).

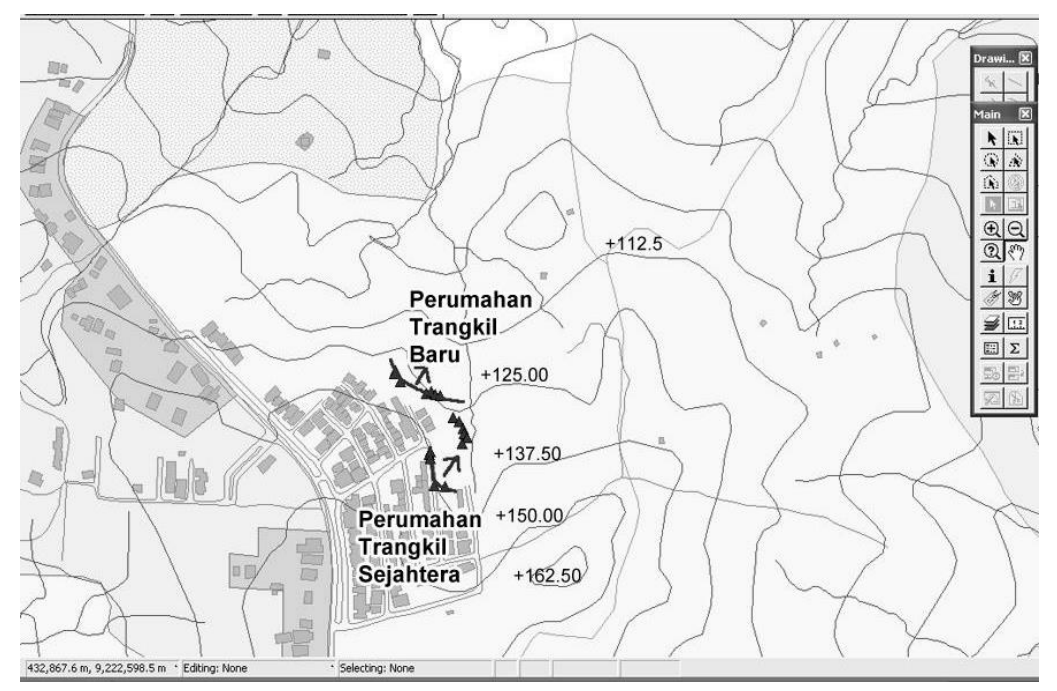

Gambar 2.Peta Topografi Daerah Penelitian Wilayah Trangkil

Luas untuk daerah penelitian gaya berat yaitu sekitar pada $700 \times 150 \mathrm{~m}$ dengan jarak atau spasi antar titik pengukuran pada peta yaitu $50 \mathrm{~m}$ dan interval kontur yang digunakan adalah sebesar $0,5 \mathrm{mGal}$. Mumlah stasiun yang digunakan dalam penelitian sebanyak 42 titik. Nilai anomaly yang dimaksud adalah gabungan antara anomaly regional, residual, dan noise (Koumetio, 2019). Hasil pembuatan kontur pada SBA ditunjukkan pada Gambar 3.

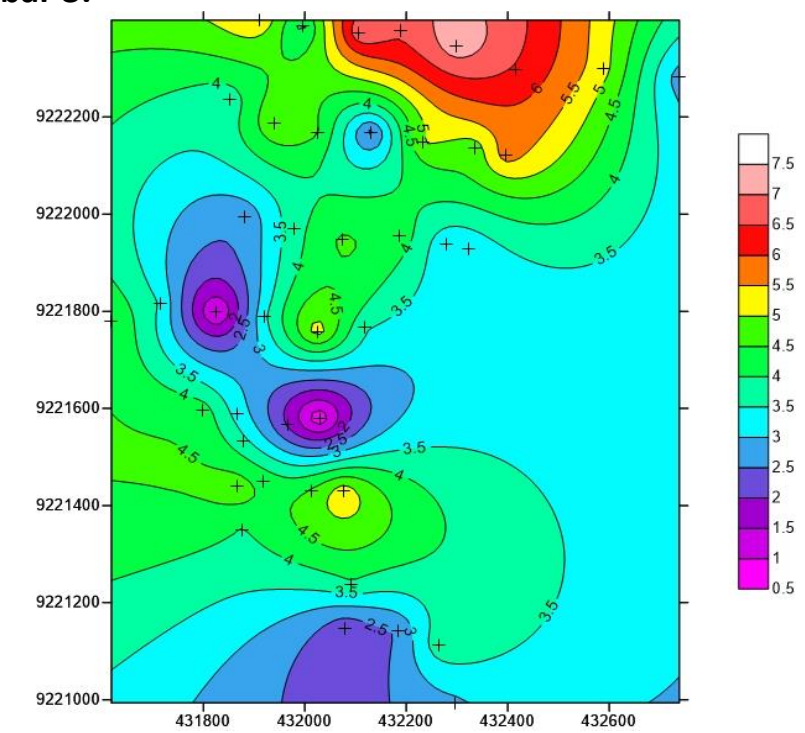

Gambar 3. Peta SBA di Daerah Penelitian Wilayah Trangkil

Persamaan yang berlaku untuk mendapatkan nilai SBA ditentukan dengan :

$$
S B A=F A A-B C
$$

Dimana :

SBA : simple bouger anomaly (mGal)

FAA : free air correction (mGal)

BC : koreksi Bouger (mGal) 
SBA memiliki pengaruh terhadap koreksi Bouger yang merupakan koreksi pada ketinggian yang memperhitungkan adanya efek pada massa batuan yang berada di antara bidang datum (geoid) dan titik pada pengamatan dengan asumsi memiliki jarak yang tak hingga dengan ketebalan tertentu. Berdasarkan pada peta pada hasil SBA di Gambar 3 terlihat bahwa nilai untuk anomalypada daerah penelitian berkisar di antara 0,5 mGal - 7,5 mGal. Nilai dengan SBA tinggi pada daerah Trangkil sebelah utara dengan nilai kisaran antara $4 \mathrm{mGal}-7 \mathrm{mGal}$. Nilai yang tinggi pada SBA diperkirakan berasal dari batuan yang memiliki densitas tinggi (Karunianto dkk, 2017). Nilai dengan SBA rendah pada selatan daerah penelitian dengan kisaran nilainya antara $0,5 \mathrm{mGal}-3 \mathrm{mGal}$. Nilai SBA yang rendah tersebut diperkirakan berasal dari batuan yang memiliki densitas yang rendah atau dikarenakan struktur batuan yang lebih turun dibandingankan dengan batuan di sekelilingnya (Justia, Hiola, \& Febryana, 2018).

Untuk mendapatkan CBA pada daerah penelitian dengan menentukan nilai SBA dan dijumlahkan dengan besarnya TC (koreksi medan). Berdasarkan hasil analisis tersebut didapatkan bahwa nilai CBA dapat dipetakan pada Gambar 4.

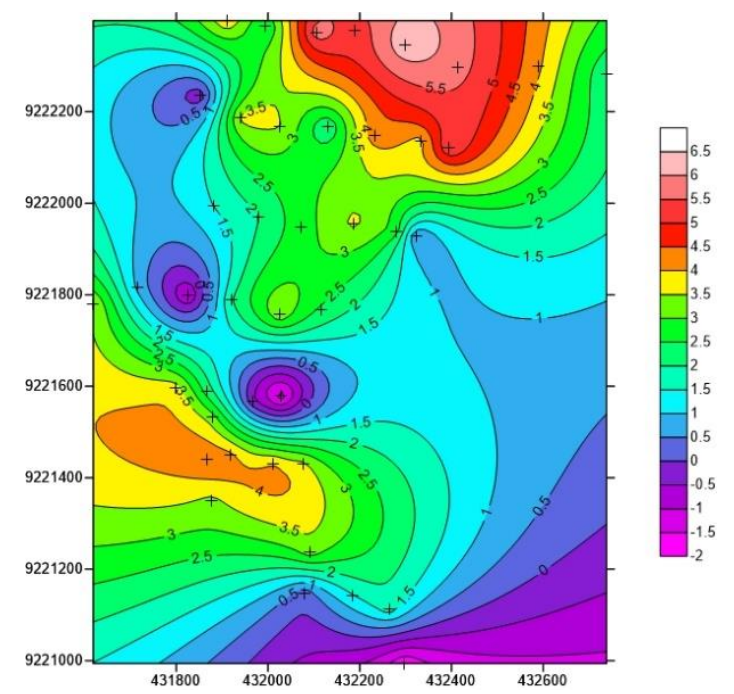

Gambar 4. Peta CBA di Daerah Penelitian Wilayah Trangkil

Peta CBA di daerah penelitian (Trangkil) merupakan peta distribusi anomaly gaya berat untuk luasan daerah $700 \times 150 \mathrm{~m}^{2}$. Peta CBA memiliki rentang anomaly pada kisaran antara -2 mGal - 6,5 mGal dengan pola sebaran anomaly rendah pada daerah penelitian sebelah selatan (ungu - biru muda). Peta CBA di daerah penelitian memiliki warna merah muda yang diindikasikan merupakan daerah anomaly gaya berat relatif paling tinggi yang memanjang dari arah utara ke selatan daerah penelitian. Nilai berada pada kisaran $2 \mathrm{mGal}-6,5 \mathrm{mGal}$. Nilai anomaly yang tinggi diduga adanya pengaruh batuan dengan nilai densitas yang tinggi (Zurek \& Williams-jones, 2013).

Anomaly dengan kisaran nilai postif dan negatif disebabkan adanya pengaruh pada tiga hal yaitu densitas batuan, posisi dan besar body batuan yang dapat mengahasilkan anomaly (Handayani \& Wardhana, 2017). CBA merupakan data yang dipergunakan untuk acuan dalam interpretasi data mengenai gravitasi baik secara kualitatif dan kuantitaif. Besaran nilai anomaly dapat ditentukan dengan reduksi topografi dalam hal ini merupakan koreksi medan terhadap gravitasi udara bebas. Nilai anomaly bouger dalam perhitungannya dipengaruhi adanya nilai gravitas observasi, nilai gravitasi normal, koreksi pada udara bebas, koreksi terrain dan koreksi Bougier(Banu, Zaenudin \& Rustadi, 2018).

\section{KESIMPULAN}

Telah dilakukan penelitian tentang struktur bawah permukaan di daerah Trangkil, Gunung Pati, Semarang, Jawa Tengah. Metode yang digunakan dalam penelitianini adalah metode gayaberat. Metodegayaberat adalah salah satu metodegeofisika yang menggunakan disribusiparameter percepatan gayaberat di permukaanbumi. Pengumpulan data dilakukan dengan menggunakan alat Gravity Meter, yang selanjutnya dilakukan pengolahan data meliputi proses koreksi yaitu tahapan pengolahan data gaya berat hasil observasi di lapangan. Hasil Simple Bougier Anomaly (SBA) untuk anomaly pada daerah penelitian berkisar di antara 0,5 mGal-7,5 mGal. Hasil Complete Bougier Anomaly (CBA) untuk anomaly pada daerah penelitian berkisar di antara 0,5 mGal-7,5 mGal. 


\section{DAFTAR PUSTAKA}

Afani, Iqbal Y. N., Yuwono, B. D. \&Bashit, N. (2019). Optimalisasi Pembuatan Peta Kontur Skala Besar menggunakan Kombinasi Data Pengukuran Terestris dan Foto Udara Format Kecil. Jurnal Geodesi Undip, 8(1), 180-189.

Banu, B., Zaenudin, A. \& Rustadi (2018). Pemodelan 3D Gaya Berat dan Analisis Struktur Detail untuk Mengembangkan Lapangan Panasbumi Kemojang. Jurnal Geofisika, 1(1), 34-42.

Cahyo, H. T., Nogroho, U. \& Widodo, A. (2014). Evaluasi Geoteknik Kelongsoran Lereng 23 Januari 2014 di Perumahan Trangkil Sejahtera Gunungpati Semarang. Jurnal Teknik Sipil dan Perencanaan, 17(02), 119-130.

Handayani, L. \& Wardhana, D. D. (2017). Eksplorasi Gaya Berat untuk Airtanah dan Topografi Batuan Dasar di Daerah Serah, Banten. Geologi dan Pertambangan, 27(2), 157-167.

Justia, M., Hiola, M. F.H. \& Febryana, N.B. (2018). Gravity Anomaly to Identify Walanae Fault Using Second Vertical Derivative Method. J. Phys. Theor. Appl, 2(1), 34-42.

Jaenudin. (2012). Laporan Akhir Praktikum Geofisika II METODE GRAVITY Laboratorium Geofisika Jurusan / Prodi Fisika Fakultas Matematika dan IImu Pengetahuan Alam Universitas Padjadjaran Geofisika II.

Karunianto, A.J., Haryanto, D., Hikmatullah, F. \& Laesanpura, A. (2017). Penentuan Anomali Gayaberat Regional dan Resisual Menggunakan Filter Gaussian Daerah Mamuju, Sulawesi Barat. Eksplorium, 38 (2), 89-98.

Koumetio, F. (2019) 'Choice of suitable regional and residual gravity maps, the case of the South-West Cameroon zone', Earth an Planetary Physics, 3, 26-32.

Torkis, R. (2012) Analisa dan Pemodelan Struktur Bawah Permukaan berdasarkan Metode Gaya Berat di Daerah Prospek Panas Bumi Gunung Lawu.

Zurek, J. \& Williams-jones, G. (2013). The shallow structure of K ì lauea caldera from high-resolution Bouguer gravity and total magnetic anomaly mapping : Insights into progressive magma reservoir growth'. Journal of Geophysical Research: Solid Earth, 118 (1), 3742-3752. 